\title{
Post-buckling of a cantilever column: A more accurate linear analysis of a classical non-linear problem
}

\section{A. Beléndez, A. Hernández, S. Gallego, M. Ortuño, C. Neipp and T. Beléndez}

Departamento de Física, Ingeniería de Sistemas y Teoría de la Señal.

Universidad de Alicante. Apartado 99. E-03080 Alicante. SPAIN

E-mail: a.belendez@ua.es

Corresponding author: A. Beléndez

Phone: +34-96-5903651

Fax: +34-96-5903464 
BELÉNDEZ VÁZQUEZ, Augusto, et al. "Post-buckling of a cantilever column: a more accurate linear analysis of a classical nonlinear problem". International Journal of Mechanical Engineering Education. Vol. 35, Issue 4 (Oct. 2007). ISSN 0306-4190, pp. 293-304

\section{Abstract}

A more accurate analytical approximate expression for the slope at any point of the elastic curve of a slender cantilever column is obtained by using a heuristic but pedagogical derivation. This derivation is based on the linearization of the non-linear differential equation that governs the post-buckling of the cantilever column. The expression proposed depends on two unknown parameters that are obtained by comparing term-by-term the power-series expansions of the approximate and exact expressions for the total length of the column. The results obtained with this new approximate expression are compared with the exact ones and with two others in the literature. The numerical results show that the two previous approximations are not nearly so accurate as the new expression proposed in this paper.

KEY WORDS: Post-buckling; Cantilever column; Approximated solutions. 
BELÉNDEZ VÁZQUEZ, Augusto, et al. "Post-buckling of a cantilever column: a more accurate linear analysis of a classical nonlinear problem". International Journal of Mechanical Engineering Education. Vol. 35, Issue 4 (Oct. 2007). ISSN 0306-4190, pp. 293-304

\section{Introduction}

The study of nonlinear problems is of crucial importance in many areas of science and engineering and most phenomena in our world are essentially nonlinear [1,2] and they are described by nonlinear equations. It is very difficult to solve nonlinear problems and, in general, it is often more difficult to get an analytic approximation than a numerical one of a given nonlinear problem [2]. Some analytic techniques have been used to find approximate solutions to nonlinear problems [3], such as perturbation techniques [4-13] or harmonic balance based methods [5, 14-18]. In general, given the nature of a nonlinear phenomenon, the approximate methods can only be applied within certain ranges of the physical parameters and or to certain classes of problems [11]. There are innumerable physical and engineering problems that can be modelled as second order, nonlinear, ordinary differential equations. One of these problems is the study of the nonlinear post-buckling of thin cantilever columns. Slender structural components, such as beams and columns, constitute basic parts of many structures [1921]. For example, slender cantilever columns are used as struts, carrying compressive loads, and mechanical systems as satellite tethers, marine cables and robotic arms employ slender elements for transmission of forces, signals and power. They are usually designed to accept large displacements but deformations are kept within the elastic regime. One of the examples illustrating the buckling phenomenon is the classical problem of the elastica [22-30]. Thin cantilever columns, being flexible, exhibit large deflections and slopes. Because of the large deflections, geometrical non-linearity occurs $[20,2,23,26,28]$. If the thickness of the cantilever column is much less than its length, the theory of elastica [21, 22] adequately describes the large, nonlinear displacements due to the loads. In this theory, deformations are due mainly to bending moments and it is usual to begin with the classical Bernoulli-Euler beam theory expressed by the nonlinear differential equation that relates deflection to load [25]. The following assumptions are inherent in this theory: (a) the column is linearly elastic, (b) the neutral axis for post-buckling of the column is inextensible, and (c) the effects of Poisson's ratio and transverse shear deformations are negligible [27]. According to the Bernoulli-Euler's equation, the bending moment is proportional to the curvature. 
BELÉNDEZ VÁZQUEZ, Augusto, et al. "Post-buckling of a cantilever column: a more accurate linear analysis of a classical nonlinear problem". International Journal of Mechanical Engineering Education. Vol. 35, Issue 4 (Oct. 2007). ISSN 0306-4190, pp. 293-304

It is important for mechanical and civil engineering students to understand the mechanics of the buckling of these structure members. In addition, the post-buckling of a slender cantilever column provides an excellent opportunity for students to use approximation concepts to study non-linear behavior associated with large-angle displacements. In this paper, the problem of the post-buckling of a cantilever column of linear elastic material subjected to a concentrated load at its free end is considered. First, we present the nonlinear differential equation for the deflection curve (elastic curve) in the general case of large deflections [22, 28]. However, we shall investigate this problem by using a different approach: a search for an analytical method to obtain an approximate solution for the slope at any point along the arc length with respect to the horizontal by using a linear analogy. If $\varphi$ is the slope at any point of the elastic curve of the column, we substitute the nonlinear $\sin \varphi$ instead of the linear function $\varphi$ (valid only for small values of $\varphi$ ), but by a function proportional to the angle $\varphi$, with the proportionality 'constant' being a function $f\left(\varphi_{0}\right)$ of the slope $\varphi_{0}$ at the free end of the column.

Several approximation schemes have been developed to investigate the situation for the postbuckling of a cantilever column, and in this paper we provide yet another. The approximate expression for the slope at the free end of the column derived here is quite accurate for very large slopes and we will see that this expression is more accurate than other similar, simple approximations suggested by us $[29,30]$. The expression of the function $f\left(\varphi_{0}\right)$ proposed in this paper depends on two parameters, $m$ and $n$, that are found by comparing term-by-term the power-series expansions of the approximate and exact expressions for the slope $\varphi_{0}$ at the free end of the column. As we can see, this implies that the expansion of the expression obtained for the length of the column to the third term is the same as the expansion of the exact solution for the length of the column.

\section{Theoretical formulation}


BELÉNDEZ VÁZQUEZ, Augusto, et al. "Post-buckling of a cantilever column: a more accurate linear analysis of a classical nonlinear problem". International Journal of Mechanical Engineering Education. Vol. 35, Issue 4 (Oct. 2007). ISSN 0306-4190, pp. 293-304

We consider a long, slender, cantilever elastic column of uniform cross section. In this study, we assume that the beam is non-extensible and strains remain small. Firstly, we assume that Bernoulli-Euler's hypothesis is valid, i.e., plane cross-sections which are perpendicular to the neutral axis before deformation remain plane and perpendicular to the neutral axis after deformation. Next, we also assume that the plane-sections do not change their shape or area. The formulation of the problem is mainly based on an important relation of the flexure theory, the moment-curvature relationship. It is possible to write the Bernoulli-Euler bending moment-curvature relationship as follows [21-29]

$$
M=\frac{E I}{\rho}
$$

where $E$ is the Young's modulus, and $M$ and $\rho$ are the bending moment and the curvature radius at any point of the column, respectively, and $I$ is the moment of inertia (the second moment of area) of the beam cross-section. Taking into account the relation $1 / \rho=\mathrm{d} \varphi / \mathrm{d} s$, where the definition of $\varphi$ and $s$ can be seen in Figure 1 , it is possible to write equation (1) as follows:

$$
M=E I \frac{\mathrm{d} \varphi}{\mathrm{ds}}
$$

This equation involves the bending moment, $M$, and governs the deflections of beams and columns made of linear type material under general loading conditions. In this equation $\varphi(s)$ is the slope at any point along the arc length with respect to the horizontal, and $s$ is the arc length measured from the fixed end.

We will consider the post-buckling of a slender cantilever column, subjected to one vertical concentrated load at the free end, by supposing that the deflection due to its own weight is null. This implies considering a massless column. As we will see this approximation is valid if the own weight of the column is much less than the critical load [28, 29]. Figure 1 shows a vertical slender cantilever column of length $L$ with a concentrated load $F$ applied at the free end of the column. In this figure $x_{f}$ and $y_{f}$ are the vertical and horizontal displacements at the free end, respectively, and $\varphi_{0}$ takes into 
BELÉNDEZ VÁZQUEZ, Augusto, et al. "Post-buckling of a cantilever column: a more accurate linear analysis of a classical nonlinear problem". International Journal of Mechanical Engineering Education. Vol. 35, Issue 4 (Oct. 2007). ISSN 0306-4190, pp. 293-304

account the slope of the column at the free end. We take the origin of the Cartesian coordinate system at the fixed end of the column and let $(x, y)$ be the coordinates of point $A$, and $s$ the arc length of the column between the fixed end and point $A$. In order to obtain the equation that governs the post-buckling of the column, we differentiate equation (2) once with respect to $s$, and we obtain:

$$
E I \frac{\mathrm{d}^{2} \varphi}{\mathrm{d} s^{2}}=\frac{\mathrm{d} M}{\mathrm{~d} s}
$$

In this equation we assume constant lengthwise cross-sectional area and moment of inertia. As we can see form Figure 1, the bending moment $M$ at a point $A$ with Cartesian coordinates $(x, y)$ is given by:

$$
M(s)=F\left(x_{f}-x\right)
$$

where $x_{f}-x$ is the distance along the $x$-axis from the section of the column at a point $A$ to the free end where force $F$ is applied (Figure 1). By differentiating equation (4) once with respect to $s$ and taking into account the relation $\sin \varphi=\mathrm{d} x / \mathrm{d} s$, we obtain:

$$
\frac{\mathrm{d} M}{\mathrm{~d} s}=-F \sin \varphi
$$

Substituting equation (5) in equation (4), we obtain the non-linear differential equation that governs the post-buckling of a slender cantilever column made of a linear material under the action of a vertical concentrated load at the free end:

$$
\frac{\mathrm{d}^{2} \varphi}{\mathrm{d} s^{2}}+\frac{F}{E I} \sin \varphi=0
$$


BELÉNDEZ VÁZQUEZ, Augusto, et al. "Post-buckling of a cantilever column: a more accurate linear analysis of a classical nonlinear problem". International Journal of Mechanical Engineering Education. Vol. 35, Issue 4 (Oct. 2007). ISSN 0306-4190, pp. 293-304

To solve equation (6) we take into account that $\varphi(0)=0$, and at the free end $\varphi(L)=\varphi_{0}$, where $\varphi_{0}$ is the unknown slope at the free end of the column (see Figure 1), and from equations (2) and (4), it follows that:

$$
\left(\frac{\mathrm{d} \varphi}{\mathrm{ds}}\right)_{s=L}=0
$$

Equation (6), although straightforward in appearance, is in fact rather difficult to solve because of the non-linearity of the trigonometric function $\sin \varphi$. There are no analytical solutions for the above differential equation. In fact, the solution is expressed in terms of elliptic integrals [28] (see Appendix).

After obtaining $\varphi$ as a function of $s$, the $x$ and $y$ coordinates of any point of the elastic curve of the cantilever beam are found as follows:

$$
\begin{aligned}
& x(s)=\int_{0}^{s} \sin (\varphi(s)) \mathrm{d} s \\
& y(s)=\int_{0}^{\mathrm{s}} \cos (\varphi(s)) \mathrm{d} s
\end{aligned}
$$

where it has been taken into account that from Figure 1, it satisfies the relations $\sin \varphi=$ $\mathrm{d} x / \mathrm{d} s$ and $\cos \varphi=\mathrm{d} y / \mathrm{d} s$. From Figure 1 , it is easy to see that the horizontal and vertical displacements, $\delta_{x}$ and $\delta_{y}$, at the free end can be obtained from equations (8) and (9) for $s$ $=L$ :

$$
\begin{gathered}
\delta_{x}=x_{f}=x(L)=\int_{0}^{\mathrm{L}} \sin (\varphi(s)) \mathrm{d} s \\
\delta_{y}=L-y_{f}=L-y(L)=L-\int_{0}^{\mathrm{L}} \cos (\varphi(s)) \mathrm{d} s
\end{gathered}
$$




\section{Some linearized approximations for the non-linear differential equation}

There are various linearized approximations for the non-linear equation (6). In the simplest of these, the analysis is limited to the case of small amplitudes (small values for $\left.\varphi_{0}\right)$. Note that if $\varphi$ is small, then the sine function can be approximated by $\sin \varphi \approx \varphi$, and the non-linear differential equation (6) becomes a linear differential equation that can easily be solved and integrating it, it can be easily seen that, for small deflections, the value of the angle at the free end of the beam, $\varphi_{0}$, disappears from the equation and we obtain that $F$ must be equal to $\pi^{2} E I / 4 L^{2}$. This implies that $F$ is not dependent on the angle $\varphi_{0}$ for small deflections. When the applied force is less than $\pi^{2} E I / 4 L^{2}$, there is no deflection of the column and hence no buckling $[25,28]$. If the applied force $F$ is gradually increased, the straight form of equilibrium becomes unstable and a small lateral force will produce a deflection which does not disappear when the lateral force is removed. The critical load (or Euler load), $F_{c r}$, is then defined as the smallest axial force which can maintain the column in a slightly bent form, and for the slender cantilever column we are analyzing its value is:

$$
F_{c r}=\frac{\pi^{2} E I}{4 L^{2}}
$$

In other linearized approximation the $\sin \varphi$ term is substituted in equation (6), not as in the previous case by the linear function $\varphi$, but by a function proportional to the angle $\varphi$, with the proportionality 'constant' being a function $f\left(\varphi_{0}\right)$ of the slope $\varphi_{0}$ :

$$
\sin \varphi \approx f\left(\varphi_{0}\right) \varphi
$$

where $f\left(\varphi_{0}\right)$ must be determined.

Substituting equation (13) into equation (6) gives 
BELÉNDEZ VÁZQUEZ, Augusto, et al. "Post-buckling of a cantilever column: a more accurate linear analysis of a classical nonlinear problem". International Journal of Mechanical Engineering Education. Vol. 35, Issue 4 (Oct. 2007). ISSN 0306-4190, pp. 293-304

$$
\frac{\mathrm{d}^{2} \varphi}{\mathrm{d} s^{2}}+\frac{F}{E I} f\left(\varphi_{0}\right) \varphi=0
$$

which is a linear differential equation easily integrable. Taking into account equation (7) and that at the free end $\varphi(L)=\varphi_{0}$, its solution is:

$$
\varphi(s)=\varphi_{0} \sin \omega s
$$

where $\omega$ is given by

$$
\omega^{2}=\frac{F}{E I} f\left(\varphi_{0}\right)
$$

and we have taken into account that equation (7) implies that $\cos (\omega L)=0$ and then $\omega=$ $\pi / 2 L$. Taking this fact into account, from equation (16) we can obtain:

$$
L=\frac{\pi}{2} \sqrt{\frac{E I}{F}} \frac{1}{\sqrt{f\left(\varphi_{0}\right)}}
$$

and the approximate value of the slope at any point of the elastic curve (equation (15)) is given by

$$
\varphi(s)=\varphi_{0} \sin \left(\frac{\pi \mathrm{s}}{2 \mathrm{~L}}\right)
$$

As can be seen in equation (17), the angle $\varphi_{0}$ depends on the length $L$.

One simple possibility is to consider the following function [29]

$$
f\left(\varphi_{0}\right)=\left(\frac{\sin \varphi_{0}}{\varphi_{0}}\right)^{n}
$$


BELÉNDEZ VÁZQUEZ, Augusto, et al. "Post-buckling of a cantilever column: a more accurate linear analysis of a classical nonlinear problem". International Journal of Mechanical Engineering Education. Vol. 35, Issue 4 (Oct. 2007). ISSN 0306-4190, pp. 293-304

where $n$ is a positive constant to be determined. In a recent paper [30] it suggested the expression

$$
f\left(\varphi_{0}\right)=\frac{\sin \left(m \varphi_{0}\right)}{m \varphi_{0}}
$$

where $m$ is a positive constant to be determined. In both equation (19) and equation (20) there is a parameter to be determined that is obtained by comparing the first terms of the power-series expansion for equation (17) with the corresponding first terms of the power-series expansion for the exact length [28-30]. The exact expression of the length $L$ is given by the expression

$$
L=\sqrt{\frac{E I}{F}} K(k)
$$

where $k=\sin ^{2}\left(\varphi_{0} / 2\right)$ and $K(k)$ is the complete elliptic integral of the first kind [31]. It is easy to see that equation (21) can be expressed as a function of the critical load (equation (12)) as follows

$$
\frac{F}{F_{c r}}=\frac{4}{\pi^{2}}[K(k)]^{2}
$$

The first two terms of the power-series expansion of equation (22) are

$$
L=\frac{\pi}{2} \sqrt{\frac{E I}{F}}\left(1+\frac{1}{16} \varphi_{0}^{2}+\ldots\right)
$$

In order to obtain the optimum value of $n$ in equation (19), equation (17) is expanding in Taylor series taking into account the expression of $f\left(\varphi_{0}\right)$ given in equation (19). Comparing this series expansion with equation (23), $n=3 / 4$ is obtained [29]. By the same procedure $m=\sqrt{3} / 2$ is calculated with the second approximation [30]. Now $f\left(\varphi_{0}\right)$ is given by equation (20). Thus, the expressions for the approximate lengths $L$ are [29] 
BELÉNDEZ VÁZQUEZ, Augusto, et al. "Post-buckling of a cantilever column: a more accurate linear analysis of a classical nonlinear problem". International Journal of Mechanical Engineering Education. Vol. 35, Issue 4 (Oct. 2007). ISSN 0306-4190, pp. 293-304

$$
L=\frac{\pi}{2} \sqrt{\frac{F}{E I}}\left(\frac{\sin \varphi_{0}}{\varphi_{0}}\right)^{-3 / 8}
$$

with the approximation considered in equation (19), and [30]

$$
L=\frac{\pi}{2} \sqrt{\frac{F}{E I}}\left(\frac{\sin \left(\sqrt{3} \varphi_{0} / 2\right)}{\sqrt{3} \varphi_{0} / 2}\right)^{-1 / 2}
$$

with equation (20). The quality of these approximations can be determined by comparing them to the exact value of the length $L$ that is given by the equation (22). However, instead of doing this, first we can compare term-by-term the power-series expansion of the exact length of the column given by

$$
L \approx \frac{\pi}{2} \sqrt{\frac{F}{E I}}\left(1+\frac{1}{16} \varphi_{0}^{2}+\frac{11}{3072} \varphi_{0}^{4}+\frac{173}{737280} \varphi_{0}^{6}+\ldots\right)
$$

with the corresponding power-series expansions of the approximate expressions for the length (from equation (24))

$$
L \approx \frac{\pi}{2} \sqrt{\frac{F}{E I}}\left(1+\frac{1}{16} \varphi_{0}^{2}+\frac{12.4}{3072} \varphi_{0}^{4}+\frac{223.5}{737280} \varphi_{0}^{6}+\ldots\right)
$$

and (from equation (25))

$$
L \approx \frac{\pi}{2} \sqrt{\frac{F}{E I}}\left(1+\frac{1}{16} \varphi_{0}^{2}+\frac{10.8}{3072} \varphi_{0}^{4}+\frac{156.9}{737280} \varphi_{0}^{6}+\ldots\right)
$$


BELÉNDEZ VÁZQUEZ, Augusto, et al. "Post-buckling of a cantilever column: a more accurate linear analysis of a classical nonlinear problem". International Journal of Mechanical Engineering Education. Vol. 35, Issue 4 (Oct. 2007). ISSN 0306-4190, pp. 293-304

If we compare term-by-term the exact equation (26) with the approximate equations (27) and (28) we can see that the two latter equations coincide with the exact equation only up to the second term $\left(\varphi_{0}^{2}\right)$, and the other terms are different. Since the first two terms of these series are identical, series (27) and (28) track series (26) closely for small amplitudes, but as the coefficients of the third (and subsequent) terms of series (27) and (28) are different for their counterparts in series (26), the difference between these approximate expressions for the length and the exact value increases as the angle $\varphi_{0}$ at the free end increases. Even so, and as shown in reference [30], equation (25) is a better approximation to the exact value than is equation (24), as can be seen by comparing the coefficients of the powers $\varphi_{0}^{4}$ and $\varphi_{0}^{6}$ of the series expansions of the exact and approximate lengths.

\section{A more accurate approximation}

We shall now see that it is possible to find a linearized approximation of equation (13) that is better than those of equations (19) and (20). As has been shown, in both equation (19) and equation (20) there is only one unknown positive constant, so when we make a comparison with the exact value this can only be done by considering the series expansion of the exact length up to the power $\varphi_{0}^{2}$. If an approximate function $f\left(\varphi_{0}\right)$ with two unknown parameters is considered, it would be possible to compare the series expansion of the approximate length obtained with this function $f\left(\varphi_{0}\right)$ with the series expansion of the exact period but in this case taking into consideration not only the coefficient of the power $\varphi_{0}^{2}$ but also that of the power $\varphi_{0}^{4}$. Taking first (equation (19)) and second (equation (20)) approximations as out starting point, we suggest the following expression for function $f\left(\varphi_{0}\right)$

$$
f\left(\varphi_{0}\right)=\left(\frac{\sin \left(m \varphi_{0}\right)}{m \varphi_{0}}\right)^{n}
$$


BELÉNDEZ VÁZQUEZ, Augusto, et al. "Post-buckling of a cantilever column: a more accurate linear analysis of a classical nonlinear problem". International Journal of Mechanical Engineering Education. Vol. 35, Issue 4 (Oct. 2007). ISSN 0306-4190, pp. 293-304

where $m$ and $n$ are positive constants to be determined. Thus the approximate length is given by

$$
L=\frac{\pi}{2} \sqrt{\frac{E I}{F}}\left(\frac{m \varphi_{0}}{\sin \left(m \varphi_{0}\right)}\right)^{n / 2}
$$

Obviously, when $n=3 / 4=0.75$ and $m=1$ we have the first approximation in equation (24) [29], whereas when $n=1$ and $m=\sqrt{3} / 2=0.8660$ we have the second approximation in equation (25) [30]. In order to obtain optimum values for the parameters $m$ and $n$ in equation (30), the power-series expansion of the right-hand side of equation (30) is performed -for example, it is easy to do this by using one of the packages of commercial software available, such as Mathematica- and we obtain

$$
L \approx \frac{\pi}{2} \sqrt{\frac{E I}{F}}\left(1+\frac{m^{2} n}{12} \varphi_{0}^{2}+\frac{\left(4 n+5 n^{2}\right) m^{4}}{1440} \varphi_{0}^{4}+\ldots\right)
$$

Comparing term by term the series expansions of equations (26) and (31) it can be seen that it is necessary to simultaneously satisfy the equations

$$
\begin{gathered}
\frac{m^{2} n}{12}=\frac{1}{16} \\
\frac{\left(4 n+5 n^{2}\right) m^{4}}{1440}=\frac{11}{3072}
\end{gathered}
$$

which makes up a system of equations with two unknowns that may be solved without too much difficulty. The solution obtained is $m=5 \sqrt{2} / 8=0.884$ and $n=24 / 25=0.96$, and equation (30) becomes

$$
L=\frac{\pi}{2} \sqrt{\frac{E I}{F}}\left(\frac{5 \sqrt{2} \varphi_{0} / 8}{\sin \left(5 \sqrt{2} \varphi_{0} / 8\right)}\right)^{12 / 25}
$$


BELÉNDEZ VÁZQUEZ, Augusto, et al. "Post-buckling of a cantilever column: a more accurate linear analysis of a classical nonlinear problem". International Journal of Mechanical Engineering Education. Vol. 35, Issue 4 (Oct. 2007). ISSN 0306-4190, pp. 293-304

that allows us to write the following transcendent equation:

$$
\sin \left(\frac{5 \sqrt{2} \varphi_{0}}{8}\right)-\frac{5 \sqrt{2}}{8}\left(\frac{F_{c r}}{F}\right)^{25 / 24} \varphi_{0}=0
$$

where we have taken into account the definition of the critical load $F_{c r}$ (equation (12)). The solution of equation (35) gives the value of the slope $\varphi_{0}$ at the free-end.

Comparing the values obtained for $n$ and $m$ with those corresponding to the approximations of a single parameter, it can be seen that the new approximation proposed in this study is closer to the second approximation (equation (20)) characterized by $m \neq 0$ and $n=0$ than to the first approximation (equation (19)) characterized by $m=0$ and $n \neq 0$. This is only logical since as shown in the previous section when compared with the series expansion of the exact length, the second approximation is better than the first one. Table 1 shows the values of $n$ and $m$ for the different approximations analyzed in this study.

In order to determine the quality of this new approximation we compare equation (26), that is, the series expansion of the exact length with the series expansion of equation (34) that we can write as follows

$$
L \approx \frac{\pi}{2} \sqrt{\frac{F}{E I}}\left(1+\frac{1}{16} \varphi_{0}^{2}+\frac{11}{3072} \varphi_{0}^{4}+\frac{164.5}{737280} \varphi_{0}^{6}+\ldots\right)
$$

It can be seen that both coincide up to the term $\varphi_{0}^{4}$ and furthermore the coefficient of the power $\varphi_{0}^{6}$ is also closer to the expansion coefficient of the exact length $(164.5 / 737280$ versus 173/737280) than the corresponding coefficients using the first (223.5/737280) and the second (156.9/737280) approximations. The values of the exact and approximate slopes $\varphi_{0}$ for different values of the quotient $F / F_{c r}$ are presented in Table 2, which shows that the new approximation given in equation (34) introduced in this paper gives a greater accuracy than the other approximations previously. Thus for example, 
BELÉNDEZ VÁZQUEZ, Augusto, et al. "Post-buckling of a cantilever column: a more accurate linear analysis of a classical nonlinear problem". International Journal of Mechanical Engineering Education. Vol. 35, Issue 4 (Oct. 2007). ISSN 0306-4190, pp. 293-304

the relative error between the approximate values and the exact value is less than $1 \%$ for $\varphi_{0}<143^{\circ}$ if we consider the approximation suggested in this paper. However, for the relative error to be less than $1 \%$ in first approximation (only $n$-parameter [29]) $\varphi_{0}$ must be $<91^{\circ}$ and in second approximation (only $m$-parameter[30]) it must be $<135^{\circ}$.

\section{Conclusions}

Postbuckling analysis of uniform slender cantilever columns under a load consisting of a tip-concentrated load has been carried out based on an approximate linearized formulation. Approximate solutions of this problem were compared with the exact results. The main result is relatively simple and accurate for very large slopes, and is better than other linearized approximations previously published [29, 30]. In fact, the percent error of this approximation remains less than $1 \%$ for angles up to $143^{\circ}$. However, it is important to point out that when one of these expressions is used to calculate the slope at the free end of the cantilever column, we are using an expression that is not exact but only a convenient approximation that allows them to easily obtain the value of the slope with sufficient accuracy.

\section{Appendix}

By integrating the nonlinear differential equation (6) it is possible to obtain the following expression for the arc length, $s$, as a function of the slope, $\varphi$, at any point along the arc length with respect to the $x$-axis $[23,31]$

$$
s=\sqrt{\frac{E I}{2 F}} \int_{0}^{\varphi} \frac{\mathrm{d} \varphi}{\sqrt{\cos \varphi-\cos \varphi_{0}}}
$$


BELÉNDEZ VÁZQUEZ, Augusto, et al. "Post-buckling of a cantilever column: a more accurate linear analysis of a classical nonlinear problem". International Journal of Mechanical Engineering Education. Vol. 35, Issue 4 (Oct. 2007). ISSN 0306-4190, pp. 293-304

The total length, $L$, corresponds to $s$ for the unknown angle, $\varphi_{0}$, at the free end of the column is $[23,31]$

$$
L=\sqrt{\frac{E I}{2 F}} \int_{0}^{\varphi_{0}} \frac{\mathrm{d} \varphi}{\sqrt{\cos \varphi-\cos \varphi_{0}}}
$$

From equation (A1) it is easy to obtain the $x$ and $y$ coordinates of the horizontal and vertical deflection at any point along the neutral axis of the cantilever column as follows $[23,32]$

$$
\begin{gathered}
x=\sqrt{\frac{2 E I}{F}}\left(\sqrt{1-\cos \varphi_{0}}-\sqrt{\cos \varphi-\cos \varphi_{0}}\right) \\
y=\sqrt{\frac{E I}{2 F}} \int_{0}^{\varphi} \frac{\cos \varphi \mathrm{d} \varphi}{\sqrt{\cos \varphi-\cos \varphi_{0}}}
\end{gathered}
$$

Equations (A1), (A2) and (A4) can be expressed in terms of elliptical integrals as follows [23]

$$
\begin{gathered}
s=\sqrt{\frac{E I}{F}} F(k, \varphi) \\
L=\sqrt{\frac{E I}{F}} F(k, \pi / 2)=\sqrt{\frac{E I}{F}} K(k) \\
y=\sqrt{\frac{E I}{F}}[2 E(k, \varphi)-F(k, \varphi)]
\end{gathered}
$$

In equations (A5), (A6) and (A7) $k=\sin ^{2}\left(\varphi_{0} / 2\right), F(k, \varphi)$ is the incomplete elliptic integral of the first kind, $F(k, \pi / 2)=K(k)$ is the complete elliptic integral of the first kind and $E(k, \varphi)$ is the incomplete elliptic integral of the second kind [31]. 
BELÉNDEZ VÁZQUEZ, Augusto, et al. "Post-buckling of a cantilever column: a more accurate linear analysis of a classical nonlinear problem". International Journal of Mechanical Engineering Education. Vol. 35, Issue 4 (Oct. 2007). ISSN 0306-4190, pp. 293-304

\section{Acknowledgements}

This work was supported by grant ACOMP06/007 from the "Generalitat Valenciana" of Spain. 
BELÉNDEZ VÁZQUEZ, Augusto, et al. "Post-buckling of a cantilever column: a more accurate linear analysis of a classical nonlinear problem". International Journal of Mechanical Engineering Education. Vol. 35, Issue 4 (Oct. 2007). ISSN 0306-4190, pp. 293-304

\section{References}

[1] D. K. Campbell, Nonlinear science: the next decade (MIT Press, Massachusetts 1992).

[2] S. Liao, Beyond Perturbation: introduction to the homotopy analysis method (CRC Press, Boca Raton FL, 2004).

[3] J. H. He, "A review on some new recently developed nonlinear analytical techniques", Int. J. Non-linear Sci. Numer. Simulation 1, 51-70 (2000).

[4] A. H. Nayfeh, Problems in Perturbations (Wiley, New York 1985).

[5] R. E. Mickens, Oscillations in Planar Dynamics Systems (World Scientific, Singapore 1996).

[6] J. H. He, "A new perturbation technique which is also valid for large parameters", J. Sound Vib. 229, 1257-1263 (2000).

[7] J. H. He, "Modified Lindstedt-Poincare methods for some non-linear oscillations. Part I: expansion of a constant”, Int. J. Non-linear Mech. 37, 309-314 (2002).

[8] J. H. He, "Modified Lindstedt-Poincare methods for some non-linear oscillations. Part II: a new transformation”, Int. J. Non-linear Mech. 37, 315-320 (2002).

[9] P. Amore and A. Aranda, "Improved Lindstedt-Poincaré method for the solution of nonlinear problems", J. Sound. Vib. 283, 1115-1136 (2005). 
BELÉNDEZ VÁZQUEZ, Augusto, et al. "Post-buckling of a cantilever column: a more accurate linear analysis of a classical nonlinear problem". International Journal of Mechanical Engineering Education. Vol. 35, Issue 4 (Oct. 2007). ISSN 0306-4190, pp. 293-304

[10] P. Amore and F. M. Fernández, "Exact and approximate expressions for the period of anharmonic oscillators", Eur. J. Phys. 26, 589-601 (2005).

[11] J. H. He, "Homotopy perturbation method for bifurcation on nonlinear problems", Int. J. Non-linear Sci. Numer. Simulation. 6, 207-208 (2005).

[12] P. Amore, A. Raya and F. M. Fernández, “Alternative perturbation approaches in classical mechanics”, Eur. J. Phys. 26, 1057-1063 (2005).

[13] A. Beléndez, A. Hernández, T. Beléndez, C. Neipp and A. márquez, “Application of the homotopy perturbation method to the nonlinear pendulum", Eur. J. Phys. 28, 93-104 (2007).

[14] R. E. Mickens, "Comments on the method of harmonic-balance”, J. Sound. Vib. 94, 456-460 (1984).

[15] R. E. Mickens, "Mathematical and numerical study of the Duffing-harmonic oscillator", J. Sound Vib. 244, 563-567 (2001).

[16] B. S. Wu and C. W. Lim, "Large amplitude nonlinear oscillations of a general conservative system", Int. J. Non-linear Mech. 39, 859-870 (2004).

[17] C. W. Lim and B. S. Wu, "Accurate higher-order approximations to frequencies of nonlinear oscillators with fractional powers", J. Sound Vib. 281, 1157-1162 (2005).

[18] A. Beléndez, A. Hernández, A. Márquez, T. Beléndez and C. Neipp, “Analytical approximations for the period of a simple pendulum", Eur. J. Phys. 27, 539-551 (2006).

[19] R. C. Hibbeler, Mechanics of Materials (MacMillan 1991). 
BELÉNDEZ VÁZQUEZ, Augusto, et al. "Post-buckling of a cantilever column: a more accurate linear analysis of a classical nonlinear problem". International Journal of Mechanical Engineering Education. Vol. 35, Issue 4 (Oct. 2007). ISSN 0306-4190, pp. 293-304

[20] M. Sathyamoorthy, Nonlinear analysis of structures (CRC Press, Boca Raton FL, 1998).

[21] D. G. Fertis, Nonlinear Mechanics (CRC Press, Boca Raton FL 1999).

[22] K. Lee, "Post-buckling of uniform cantilever column under a combined load", Int. J. Non-linear Mech. 36, 813-816 (2001).

[23] T. Beléndez, C. Neipp and A. Beléndez, "Numerical and experimental analysis of a cantilever beam: A laboratory project to introduce geometric nonlinearity in Mechanics of Materials", Int. J. Engng. Ed. 19 885-892 (2003).

[24] T. Beléndez, M. Pérez-Polo, C. Neipp and A. Beléndez, "Numerical and experimental analysis of large deflections of cantilever beams under a combined load”, Phys. Scripta T118, 61-65 (2005).

[25] S. P. Timoshenko and J. M. Gere, Theory of Elastic Stability, 2 ${ }^{\text {nd }}$ Edition, (McGraw-Hill International Editions, Singapore 1961).

[26] T. Beléndez, C. Neipp and A. Beléndez,"Large and small deflections of a cantilever beam", Eur. J. Phys. 23, 371-379 (2002).

[27] B. K. Lee, J. F. Wilson and S. J. Oh, "Elastica of cantilevered beams with variable cross sections", Int. J. Non-linear Mech. 28, 579-589 (1993).

[28] T. Beléndez, C. Neipp and A. Beléndez, "An integrated project for teaching the post-buckling of a slender cantilever bar", Int. J. Mech. Engng. Ed. 32, 78-92 (2004). 
BELÉNDEZ VÁZQUEZ, Augusto, et al. "Post-buckling of a cantilever column: a more accurate linear analysis of a classical nonlinear problem". International Journal of Mechanical Engineering Education. Vol. 35, Issue 4 (Oct. 2007). ISSN 0306-4190, pp. 293-304

[29] T. Beléndez, C. Neipp and A. Beléndez, "Post-buckling of a slender cantilever bar: linear analysis of a nonlinear problem", Rev. Esp. Fis. 18 (3), 41-46 (2004).

[30] A. Beléndez, A. Hernández, A. Márquez, T. Beléndez and C. Neipp, "Postbuckling of a cantilever column: Linear analysis of a non-linear problem", Int. J. Mech. Engng. Ed. (accepted for publication).

[31] P. F. Byrd and M. D. Friedman, Handbook of Elliptical Integrals for Engineers and Scientist (Springer-Verlag, New York 1971).

[32] L. D. Landau and E. M. Lifshitz, Course of Theoretical Physics, Vol. 7: theory of Elasticity (Pergamon Press, Oxford 1986). 
BELÉNDEZ VÁZQUEZ, Augusto, et al. "Post-buckling of a cantilever column: a more accurate linear analysis of a classical nonlinear problem". International Journal of Mechanical Engineering Education. Vol. 35, Issue 4 (Oct. 2007). ISSN 0306-4190, pp. 293-304

\section{TABLES}

Table 1.- Values of parameters $n$ and $m$ for the different approximations analyzed in this paper.

Table 2.- Exact and approximate values of $\varphi_{0}$ and relative errors as a function of $F / F_{c r}$. 
BELÉNDEZ VÁZQUEZ, Augusto, et al. "Post-buckling of a cantilever column: a more accurate linear analysis of a classical nonlinear problem". International Journal of Mechanical Engineering Education. Vol. 35, Issue 4 (Oct. 2007). ISSN 0306-4190, pp. 293-304

\section{FIGURE CAPTIONS}

Fig. 1.- Slender cantilever column loaded with an external vertical concentrated load at the free end. 
BELÉNDEZ VÁZQUEZ, Augusto, et al. "Post-buckling of a cantilever column: a more accurate linear analysis of a classical nonlinear problem". International Journal of Mechanical Engineering Education. Vol. 35, Issue 4 (Oct. 2007). ISSN 0306-4190, pp. 293-304

\section{Table 1}

\begin{tabular}{lcc}
\hline Approximation & $n$ & $m$ \\
\hline Equation (21) [28] & 0.75 & 1.0000 \\
\hline Equation (22) [29] & 1.00 & 0.8660 \\
\hline Equation (32) [this paper] & 0.96 & 0.8839 \\
\hline
\end{tabular}


BELÉNDEZ VÁZQUEZ, Augusto, et al. "Post-buckling of a cantilever column: a more accurate linear analysis of a classical nonlinear problem". International Journal of Mechanical Engineering Education. Vol. 35, Issue 4 (Oct. 2007).

\section{Table 2}

\begin{tabular}{|c|c|c|c|c|}
\hline \multirow[b]{2}{*}{$F / F_{c r}$} & \multirow{2}{*}{$\begin{array}{c}\varphi_{0} \\
\text { (exact) }\end{array}$} & $\varphi_{0}$ (relative error) & $\varphi_{0}$ (relative error) & $\varphi_{0}$ (relative error) \\
\hline & & $\begin{array}{c}n=3 / 4 \quad m=0 \\
{[29]}\end{array}$ & $\begin{array}{c}n=0 \quad m=\sqrt{3} / 2 \\
{[30]}\end{array}$ & $\begin{array}{c}n=24 / 25 \quad m=5 \sqrt{2} / 8 \\
\text { (this paper) }\end{array}$ \\
\hline 1.00000 & $0^{\mathrm{o}}$ & $0^{\circ}(0.00 \%)$ & $0^{\circ}(0.00 \%)$ & $0^{\circ}(0.00 \%)$ \\
\hline 1.01540 & $20^{\circ}$ & $19.99^{\circ}(0.05 \%)$ & $20.00^{\circ}(0.00 \%)$ & $20.00^{\circ}(0.00 \%)$ \\
\hline 1.06366 & $40^{\circ}$ & $39.93^{\circ}(0.18 \%)$ & $40.01^{\circ}(0.03 \%)$ & $40.00^{\circ}(0.00 \%)$ \\
\hline 1.15172 & $60^{\circ}$ & $59.75^{\circ}(0.42 \%)$ & $60.04^{\circ}(0.07 \%)$ & $60.01^{\circ}(0.02 \%)$ \\
\hline 1.29389 & $80^{\circ}$ & $79.41^{\circ}(0.74 \%)$ & $80.12^{\circ}(0.15 \%)$ & $80.03^{\circ}(0.04 \%)$ \\
\hline 1.51839 & $100^{\circ}$ & $98.81^{\circ}(1.19 \%)$ & $100.31^{\circ}(0.31 \%)$ & $100.12^{\circ}(0.12 \%)$ \\
\hline 1.88480 & $120^{\circ}$ & $117.90^{\circ}(1.75 \%)$ & $120.71^{\circ}(0.59 \%)$ & $120.36^{\circ}(0.30 \%)$ \\
\hline 2.54227 & $140^{\circ}$ & $136.60^{\circ}(2.43 \%)$ & $141.62^{\circ}(1.16 \%)$ & $140.99^{\circ}(0.71 \%)$ \\
\hline 4.03010 & $160^{\circ}$ & $155.04^{\circ}(1.80 \%)$ & $164.11^{\circ}(2.57 \%)$ & $162.88^{\circ}(1.80 \%)$ \\
\hline
\end{tabular}


BELÉNDEZ VÁZQUEZ, Augusto, et al. "Post-buckling of a cantilever column: a more accurate linear analysis of a classical nonlinear problem". International Journal of Mechanical Engineering Education. Vol. 35, Issue 4 (Oct. 2007). ISSN 0306-4190, pp. 293-304

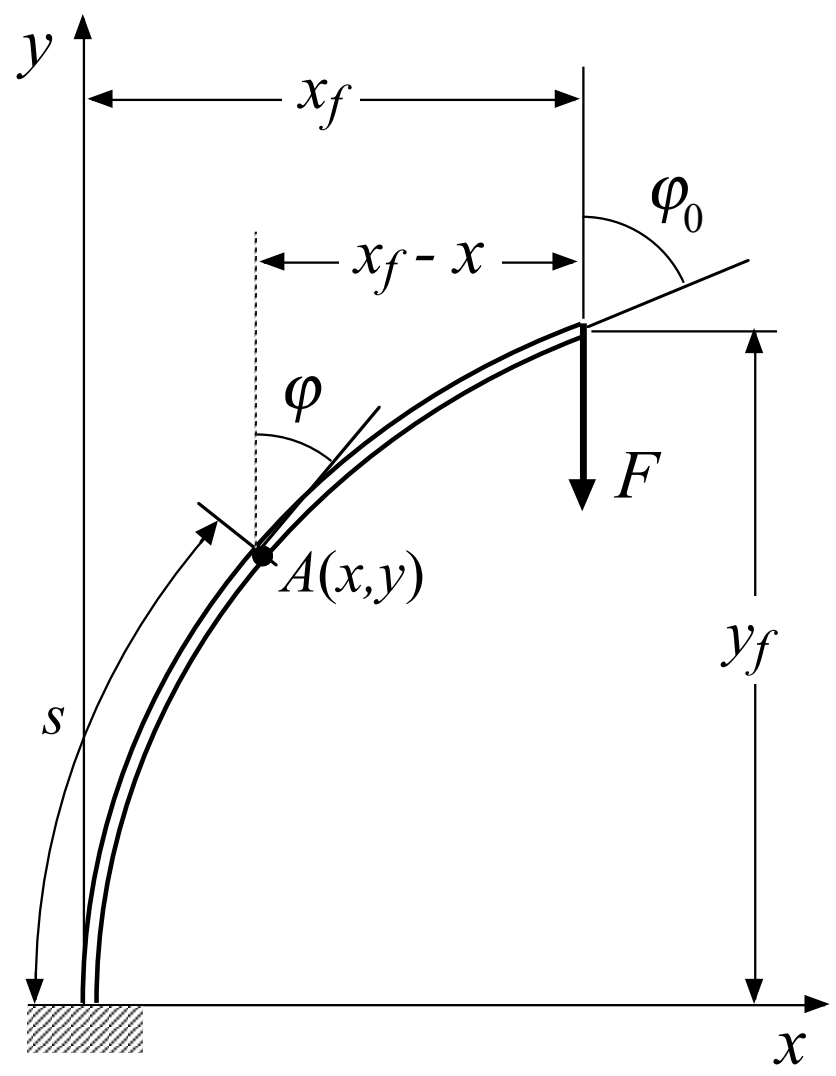

FIGURE 1 